$\begin{array}{llllllllllllll}\text { A C T A } & \text { C H E M I C A } & \text { S C A N D I N A V I C A } & \text { (1 95 } 0) & 942-947\end{array}$

\title{
A Method for the Determination of Tracer Phosphate in Biological Material
}

\author{
L. ER N T ER, R. Z E T T ERSTRöM and O. L I N D B ER G \\ Department of Metabolic Research, Wenner Gren Institute, University of Stockholm, \\ Stockholm, Siveden
}

T he determining of the labelling in connection with studies of phosphate metabolism made with the aid of labelled phosphate, is generally performed in the following way:

In a sample containing orthophosphate the phosphate is determined e. $g$. according to Fiske and Subbarow ${ }^{1}$ or to some modification of their method. The radioactivity is determined in a Geiger-Müller-counter after precipitation of the orthophosphate in the sample, together with phosphate carrier as $\mathrm{MgNH}_{4}$-salt. The specific activity $=$ number of impulses per minute emitted per microg. of $\mathrm{P}$. is then calculated according to ex. Lindberg ${ }^{2}$.

Three essential faults are connected with this method. The radioactivity and the phosphate are determined on different solutions, one of them acid and the other alkaline. In samples containing acid-labile phosphate correct values are obtained for the number of impulses, but the phosphate values are too high. If the sample contains alkali-labile phosphate, correct phosphate values but too high a number of impulses are obtained. If there are small amounts of orthophosphate in the sample, but great amounts of highly labelled esters, esterified phosphate is adsorbed on the phosphate precipitate and the number of impulses obtained is too high. The latter applies to an even greater extent if inorganic pyrophosphate is present in the solution.

We have found the method discussed below generally applicable.

Orthophosphate is determined according to Martin and Doty ${ }^{3}$, whose method is a modification of that introduced by Beerneblom and Chain 4. On determination according to Martin and Doty the derivatives of phosphomolybdic acid which have been formed, are shaken up into a mixture of isobutanol and benzene $(1: 1)$. The formed cerulomolybdate is determined 
colorometrically, after the addition of $\mathrm{H}_{2} \mathrm{SO}_{4}$ dissolved in ethanol, and of $\mathrm{SnCl}_{2}$ to the drawn-off isobutanol-benzene phase.

The method of Martin and Doty has been modified to make possible the direct determination of the specific activity of the orthophosphate fraction in a sample. In order to determine radioactivity, a sample is taken directly from the isobutanol-benzene phase, pipetted onto a small aluminium plate, and dried and placed under a Geiger-Müller tube.

\section{METHOD}

Reagents: According to Martin and Doty.

1. Isobutanol-benzene, $1: 1$.

2. $10 \mathrm{~N} \mathrm{H}_{2} \mathrm{SO}_{4}$.

3. $10 \%$ ammonium molybdate.

4. $32 \mathrm{ml}$ conc. $\mathrm{H}_{2} \mathrm{SO}_{4}$ dissolved in $968 \mathrm{ml}$ abs. (99.5\%) ethanol.

5. $10 \mathrm{~g} \mathrm{SnCl}_{2} \cdot 2 \mathrm{H}_{2} \mathrm{O}$ dissolved in $25 \mathrm{ml}$ conc. $\mathrm{HCl}$, kept in a refrigerator.

6. Reagent 5 diluted 200 times with $\mathrm{N} \mathrm{H}_{2} \mathrm{SO}_{4}$, is to be freshly prepared immediately before each determination.

If the sample is deproteinized, e.g. a TCA extract, the reagents mentioned above are sufficient. If, on the other hand, the sample is not deproteinized, or is a homogenate, the deproteinization can be performed by using silico-tungstic acid (according to Martin and Doty) in the tube in which the phosphomolybdic acid is formed.

\section{RESULT}

$3 \mathrm{ml}$ of a nearly sulphate-free sample (the content of sulphate in a biological extract does not interfere with the determination) containing 2-16 microgram $\mathrm{P}$, is mixed with $5 \mathrm{ml}$ of reagent $1,0.5 \mathrm{ml}$ reagent 2 and $0.5 \mathrm{ml}$ reagent 3. The tube is stoppered, with a ground glass stopper for preference, and shaken vigorously for 15 seconds. After separation, which generally takes place rapidly without centrifugation, approximately $2.5 \mathrm{ml}$ of the upper phase is sucked off with the aid of a tight, locked Krogh-syringe, which contains the desired volume when full. The syringe is washed quantitatively with reagent 4. The combined sample and wash solutions are mixed with $0.5 \mathrm{ml}$ of reagent 6. The color-intensity may be determined at $640 \mathrm{~m} \mu$ in a KlettSummerson photometer. A Beckman-spectrophotometer shows two absorption-maxima in formed molybdenum-blue, one at 625 and one at $730 \mathrm{~m} \mu$. The color-intensity therefore should be measured in a Beckman-spectrophotometer at one of these wavelengths.

When determining the radioactivity, a smaller syringe which takes about $0.2 \mathrm{ml}$ is used thus permitting a very accurate testing. The sample is drawn directly from the isobutanol-benzene phase and transferred onto an alumi- 
nium plate containing a small filterpaper. When the sample is dry the radioactivity may be determined by placing the plate in an electron-counter. If the specific activity is low another $0.2 \mathrm{ml}$ can be pipetted off and added to the dried sample. It is possible to carry out a determination at a very low specific activity in the following way: In a separatory funnel a $3 \mathrm{ml}$ sample of orthophosphate in the form of phosphomolybdic acid is shaken with $5 \mathrm{ml}$ of isobutanol-benzene. When the phases are well separated $1 \mathrm{ml} 5 \% \mathrm{Na}_{2} \mathrm{CO}_{3}$ is added to the isobutanol-benzene phase and the mixture is shaken for 15 seconds, whereupon the phosphate migrates quantitatively into the water phase. From this $0.2 \mathrm{ml}$ may be pipetted off for activity-analysis. If the whole amount is needed for determination, the whole solution may be precipitated with Fiskes reagent after the addition of orthophosphate as a carrier.

The latter procedure has the advantage that the magnesium ammonium phosphate precipitation does not adsorb highly labelled esterified phosphate, which would cause the specific activity of the orthophosphate to become too high.

In the beginning a considerably more concentrated sample may be taken. For a phosphate determination a suitable amount of the benzeneisobutanol phase is sucked off, after which it is diluted to 5 or $10 \mathrm{ml}$ with reagent 4 and $0.5 \mathrm{ml}$ of reagent is then added. The method is illustrated by the following experiment.

Fifteen hours before the experiment a white rat had been given $0.5 \mathrm{mC} \mathrm{P}^{32}$ intraperitoneally. The animal was anaesthetized with amytol. Muscles were then taken from both back-legs and immediately frozen in carbondioxide chilled acetone. The muscles were extracted with cold $10 \%$ TCA.

The amount of orthophosphate per unit volume present in the extract and the specific activity of the orthophosphate were determined immediately, before the hydrolysis of the creatinephosphate had time to take place.

If a cold sample containing ortho- and creatine phosphate is pipetted off into a reagent-solution and then cooled in ice-water, less than $1 \%$ hydrolysis of the creatinephosphate occurs, whereas the orthophosphate is transformed quantitatively into phosphomolybdic acid and as such migrates into the benzene-isobutanol phase.

Fig. 1 shows hydrolysis of creatine-phosphate in the presence of acid molybdate; after 30 minutes the creatine-phosphate is almost completely hydrolyzed. Under these circumstances ATP or ADP is not hydrolyzed ${ }^{5}$. This phase may be sucked off completely since the orthophosphate present in the sample as phosphomolybdic acid has been transferred into the isobutanol phase. The water-phase is then allowed to stand 30 minutes at room-temperature, while new phosphomolybdic acid is formed from the hydrolyzed creatinephosphate. The newly formed phosphomolybdic acid may 
Fig. 1. Hydrolysis of creatine-phosphate at $20^{\circ} \mathrm{C}$ in presence of phosphate-determining reagent.

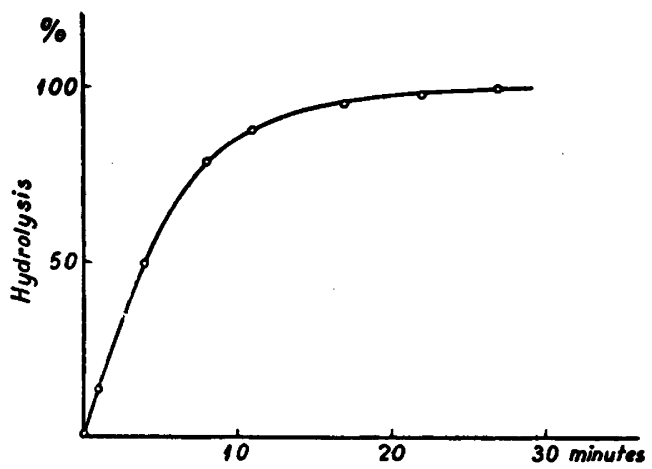

be shaken up into the upper phase, after the addition of a further $5 \mathrm{ml}$ of isobutanol-benzene, thus obtaining a direct value for creatine phosphate.

In order to determine the labile ATP-phosphate, the sum of ortho- and creatine-phosphate should be deducted from the value obtained when the 3 $\mathrm{ml}$ sample is hydrolyzed for 20 minutes at $100^{\circ}$ with $0.5 \mathrm{ml} 10 \mathrm{~N} \mathrm{H}_{2} \mathrm{SO}_{4}$. The total phosphate is determined after combustion with $0.05 \mathrm{ml}$ in excess of the amount of $\mathrm{H}_{2} \mathrm{SO}_{4}$ necessary for phosphate analysis and one drop of $\mathrm{H}_{2} \mathrm{O}_{2}$.

Table 1 shows the result of the analyses carried out on the TCA extract of muscles.

Upon precipitation of radio-active orthophosphate with Fiskes reagent using added phosphate "carrier" and in the presence of large amounts of active esterified phosphate or active pyrophosphate, the specific activity of the orthophosphate is too high because of the adsorption on the magnesium-ammoniumphosphate crystals. Inorganic pyrophosphate seems to precipitate largely with Fiskes reagent in the presence of large amounts of orthophosphate.

Table 1. Phosphate fractions separated by acid hydrolysis, from a TCA-extract of muscles.

Number of impulses/minute and extinction for $1 \mathrm{ml}$ of the original sample. $2.56 \mathrm{ml}$ was taken from the isobutanolbenzene phase for the phosphate determination. According to the determination with standard orthophosphate under these conditions an estimation of 25 corresponds to one microgram $P$. $0.18 \mathrm{ml}$ was used for radioactivity measuring.

\section{Ortho-P}

Creatine-P

Labile ATP-P

Residual-P
Microg $\mathbf{P}$

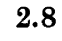

6.5

7.8

8.4
Impulses/min.

3160

8470

10400

2540
Spec.act. 
Table 2 shows the analytical results of a sample containing small amounts of orthophosphate and comparatively large amounts of ATP. The value for the specific activity of the orthophosphate is in agreement with the values obtained directly from the TCA-extract. The specific activity of the orthophosphate will be approximately twice as high as that of the labile ATPphosphate, when measuring radio-activity with the aid of precipitation, according to Fiske.

Table 3 shows a comparison between the values obtained with the two methods for specific activity on different hydrolysis fractions in the presence of radioactive inorganic pyrophosphate. The table shows that only the method described here is applicable under these circumstances. The inorganic pyrophosphate precipitation is almost complete when using Fiskes reagent in the presence of orthophosphate.

Table 2. Different hydrolysis fractions in an impure ATP-preparation.

The same TCA-extract as before was precipitated after spontaneous hydrolysis of creatine phosphate with mercury acetate at $\mathrm{pH}$ 4.0. The precipitate in TCA-solution was decomposed with $\mathrm{H}_{2} \mathrm{~S}$, the mercuric sulfide was filtered off and $\mathrm{H}_{2} \mathrm{~S}$ removed by aeration. The rest of the procedure is the same as in the preceding experiment. Ext. $27.2=1$ microg $P$.

$\begin{array}{lccc} & \text { Microg } P & \text { Impulses/min. } & \text { Spec.act. } \\ \text { Ortho-P } & 1.0 & 1110 & 1110 \\ \text { Labile ATP-P } & 8.6 & 10200 & 1190 \\ \text { Residual-P } & 4.3 & 1200 & 280\end{array}$

Table 3. Comparison of specific activities determined according to this method and as for example determined by Lindberg ${ }^{2}$, in the presence of radioactive pyrophosphate.

The impure ATP-preparation, prepared according to Table 2, was hydrolized for 30 minutes at $100^{\circ}$ with $\mathrm{Ba}(\mathrm{OH})_{2}$, $\mathrm{pH} 9.0$, thus the ATP is hydrolized into adenylic acid and inorganic pyrophosphate ${ }^{6}$. Barium is precipitated as sulphate, the sulphate excess is kept so low that the sulphate concentration cannot influence the phosphate determination.

Determination according to precipitating method (2).

Ortho-P Impulses/min. Microg $\mathbf{P}$

Easily hydrolyzable $P$ 6880 Residual-P 3200

Determination according to this method.

Ortho-P Impulses/min.

Easily hydrolizable $\mathbf{P}$

Residual-P

Total-P

\section{Microg $\mathrm{P}$}

3.5

6.9

4.2

14.6
Spec.act. 980

1130

230 820 


\section{SUMMARY}

1. Description of a method allowing a quick and exact determination of the specific activity of orthophosphate present in a sample. This can be done even in the presence of creatine phosphate and radioactive pyrophosphate.

2. After determination of the percentage of orthophosphate and of the specific activity of the orthophosphate, the amount of creatinephosphate and its specific activity may be determined in the same sample.

3. In a homogenate the amount of orthophosphate and its specific activity can be determined in the same tube and at the same time as deproteinization is being carried out.

\section{REFERENCES}

1. Fiske, C. H., and Subbarow, Y. J. Biol. Chem. 66 (1925) 375.

2. Lindberg, O. Arkiv Kemi, Mineral. Geol. A 23 (1946) no. 2.

3. Martin, J. M., and Doty, D. M. Anal. Chem. 21 (1949) 965.

4. Beerenblum, I., and Chain, E. Biochem. J. 32 (1938) 205.

5. Ennor, A. H., and Stocken, L. A. Biochem. J. 42 (1948) 549.

6. Lohman, K. Biochem. Z. 254 (1932) 381.

Received June 2, 1950. 